\title{
A informática no processo de ensino aprendizagem do Instituto Federal Baiano - Campus Guanambi
}

\section{Computer in teaching learning process of Instituto Federal Baiano, Campus Guanambi}

\begin{abstract}
Resumo:
O trabalho tem por objetivo geral descrever o uso da informática na prática pedagógica dos docentes do Instituto Federal Baiano - Campus Guanambi. Analisamos o nível de familiaridade dos docentes com a informática; identificamos os elementos objetivos e subjetivos que condicionam o uso do Laboratório de Informática; identificamos as possibilidades e potencialidades do uso da informática como ferramenta de ensino na IF Baiano - Campus Guanambi. Este estudo foi realizado com 33 professores que compõem o quadro docente do IF Baiano - Campus Guanambi e para isso foi utilizada uma abordagem descritiva, de caráter quantitativo, fundamentada em um quadro conceitual composto a partir da revisão da literatura e em dados coletados a partir da aplicação de questionários. Com essa descrição do uso da informática no IF Baiano - Campus Guanambi, podemos oferecer instrumentos para a elaboração de propostas de melhoria de uso das tecnologias existentes na instituição, onde os docentes possam desenvolver suas atividades.

Palavras-Chave: Informática. Prática Pedagógica. Ensino/ Aprendizagem.
\end{abstract}

Abstract:

The aim of this paper was to describe the general use of computing in the pedagogical practice at Instituto Federal Baiano, Campus Guanambi. There was analyzed the level of teachers' familiarity with computing. There was identified the objective and subjective elements that conditioned the use of the Computer Laboratory, the possibilities and potential use of computer technology as a teaching tool at IFBaiano, Guanambi Campus. The study was conducted with 33 teachers of the institution. There were used a descriptive approach, quantitative, grounded in a conceptual framework made up from the literature review and on data collected from the questionnaires. With this description of the use of computing at IFBaiano, Guanambi Campus, tools were offered for drawing up proposals for improved the teachers' use of the existing technologies in their activities in the Campus.

Keywords: Computing. Pedagogical Practice. Teaching and Learning.

FERREIRA, Naidson Clayr Santos. A Informática no Processo de Ensino Aprendizagem do Instituto Federal Baiano - Campus Guanambi. Informática na Educação: teoria \& prática, Porto Alegre, v. 13, n. 1, p. 140-155, jan./jun. 2010.

\section{Naidson Clayr Santos Ferreira \\ Instituto Federal Baiano}

\section{Introdução}

V ivemos numa sociedade onde o conhecimento, a informação e o domínio da informática, são pontos importantes e decisivos para que uma pessoa sobreviva num mundo marcado pelos avanços tecnológicos. Os educadores, como integrantes dessa sociedade, vivenciam estas transformações.

Nesta etapa de mudanças, o professor tem também como principal objetivo ensinar os educandos onde e como buscar a informação, como tratá-la e como utilizá-la, bem como de promover a aprendizagem, fazendo com que os mesmos construam o conhecimento de forma individual e em grupo, reunidos por área de interesse. Para isso o professor deve saber manusear e usar com segurança a informática, de forma adequada, manter-se sempre informado, estar sempre procurando experiências bem sucedidas na área, de modo que possa aprimorar sua prática pedagógica, criando assim uma interação professor-alunoinformática.

Verifica-se também a necessidade da adoção de propostas educativas no processo de formação de profissionais que sejam capazes de dominar e utilizar a informática (computador, softwares educacionais, datashow) como ferramenta no mercado de trabalho e, também, como estratégia para o desenvolvimento. 
Diante do exposto partimos da hipótese que a utilização da informática (computador; internet; softwares educacionais) por parte dos professores do Instituto Federal de Educação, Ciência e Tecnologia Baiano - Campus Guanambi antiga Escola Agrotécnica Federal Antônio José Teixeira contribui significativamente para o estímulo de práticas inovadoras no IF Baiano - Campus Guanambi, o que constitui fator de qualidade do ensino.

\section{0 uso da informática na prática educativa no IF Baiano - Campus Guanambi}

O avanço rápido da informática tem trazido significativas contribuições para o progresso cultural e científico, principalmente quando possibilita o suporte tecnológico para congregar e difundir conhecimento. Por essa razão, o meio produtivo em que a IF Baiano - Campus Guanambi se encontra exige cada vez mais pessoal com competências e habilidades desenvolvidas em informática.

O IF Baiano - Campus Guanambi possui uma Unidade de Processamento de Dados (UPD) que conta com cinco funcionários. Desses cinco funcionários, três têm nível superior e exercem o cargo de Analista de sistemas do Instituto e os outros dois possuem nível técnico e exercem o cargo de Técnico em informática. No organograma, a UPD está diretamente ligada à Direção Geral. A Coordenação da UPD está sob a responsabilidade de um desses funcionários e os outros o auxiliam na coordenação. O Instituto não possui alunos monitores de informática.

Na UPD, os seguintes serviços são realizados: 1) manutenção e montagem de computadores; 2) administração da rede de computadores e servidores; 3) especificação técnica dos equipamentos de informática que serão adquiridos pelo IF Baiano - Campus Guanambi; 4) desenvolvimento e administração do site do IF Baiano - Campus Guanambi onde são colocadas informações da instituição; 5) suporte técnico de trabalhos realizados pelos departamentos do instituto.

O IF Baiano - Campus Guanambi tem uma média de 200 máquinas assim distribuídas: 51 notebooks, que foram adquiridos no ano de 2008, para uso dos docentes e dos chefes de departamentos; 60 computadores divididos em dois laboratórios de informática; 10 computadores que estão na sala de internet para acesso dos discentes e o restante dos computadores está distribuído nos departamentos do IF Baiano - Campus Guanambi. Todos esses equipamentos têm acesso à internet. O IF Baiano - Campus Guanambi possui uma média de 40 alunos por turma que usam o Laboratório de informática.

Além desses computadores, o IF Baiano Campus Guanambi possui outras tecnologias da área de informática que auxiliam no funcionamento administrativo e pedagógico da instituição.

São essas as tecnologias: um software que atende a Coordenação de Registros Escolares (CRE), Almoxarifado, Coordenação Geral de Assistência ao Educando (CGAE), um link de $2 \mathrm{MB}$ da Rede Nacional de Pesquisa (RNP), na qual permite que o IF Baiano - Campus Guanambi tenha acesso à internet 24 horas, 30 datashows, softwares educacionais e um sistemas de antenas para redes wireless que cobre todo o instituto.

Os softwares educacionais utilizados pelo IF Baiano - Campus Guanambi foram adquiridos por meio de um projeto junto a Fundação Vitae. Esses softwares foram escolhidos pela Unidade de Processamento de Dados - UPD de acordo as disciplinas que são ministradas no Instituto. Os softwares educacionais se encontram instalados nos computadores de um dos Laboratórios de informática.

\subsection{Apresentação do problema}

Com várias justificativas, as tecnologias invadem as instituições escolares, demandando dos professores um posicionamento quanto ao quê e como fazer para otimizar os recursos da informática para o benefício do trabalho pedagógico.

O problema começa com o processo de informatização das escolas, onde não se tem um planejamento da área de informática, simplesmente criam-se os laboratórios de informática e não tem uma pessoa responsável por aquele setor. Devemos também levar em consideração, apesar da própria política do governo federal de investir nessa área de tecnologia, que ocorre um investimento muito alto em laboratórios de informática para as escolas e os mesmos são subutilizados, ou seja, às vezes encontramos escolas bem equipadas com to- 
dos os equipamentos de informática possíveis, mas os mesmos não são utilizados em sua total potencialidade.

A escola, hoje em dia, vive em uma sociedade cheia de informações instantâneas, superficiais e fragmentadas, marcada por um período efêmero. Os computadores entram no ambiente escolar dentro de um campo mais amplo, que é a informática.

Baseado nessas mudanças, Moran, Masseto e Behrens (2000, p. 139) afirmam que "[...] não é a tecnologia que vai resolver ou solucionar o problema educacional do Brasil. Poderá colaborar, no entanto, se for usada adequadamente, para o desenvolvimento educacional de nossos estudantes [...]".

Ainda nesse contexto, Souza (2002, p. 02) afirma que "[...] ignorar a existência do computador como elemento potencialmente rico para o ensino é tão grave quanto crer que ele resolverá todos os problemas de nosso sistema educacional. É preciso avaliar e planejar."

A simples utilização da informática não ampara a eficiência do processo de ensino-aprendizagem, ainda mais se essa utilização tiver como finalidade o ingresso das tecnologias na escola, isto é, se a preocupação não for o professor e o aluno que quer aprender.

Neste contexto, é imprescindível que os cursos oferecidos pela instituição disponham de laboratórios que instrumentalizem este processo didático-pedagógico.

Diante desse panorama, o funcionamento do Laboratório de Informática ocorre da seguinte maneira: Tanto os professores da Área Diversificada ${ }^{1}$ como da Base Comum ${ }^{2}$ utilizam o Laboratório de Informática para ministrar as aulas. As disciplinas usam o Laboratório de Informática em situações esporádicas e de acordo com o horário disponível do Laboratório de Informática. Os professores que têm interesse em ministrar alguma aula no Laboratório de Informática, verificam junto aos professores de informática os horários de aula e nos períodos em que não há aula marcada deixam reservado o laboratório para que possam ministrar suas aulas.

Essas aulas são utilizadas para que os alu-

1 Professores na qual ministram as disciplinas da área agropecuária, tais como: Mecanização Agrícola, Informática, Topografia, Zootecnia, Bovinocultura de corte, etc.

2 Professores na qual ministram aulas do Ensino Médio, tais como: Geografia, História, Matemática, Química, etc. nos façam pesquisas das determinadas disciplinas, com o objetivo de buscar na internet material para se montar seminários e outros trabalhos. Os professores reconhecem que 0 IF Baiano - Campus Guanambi tem um Laboratório de Informática, com acesso a internet e alguns softwares educacionais, disponibilizados para suas atividades de ensino e pesquisa, mas mesmo assim não os utilizam.

Isto posto, surgem as seguintes questões: porque os docentes do IF Baiano - Campus Guanambi não utilizam o laboratório de informática? Será que os professores do IF Baiano - Campus Guanambi estão preparados para utilizar a informática na sua prática pedagógica? Os docentes do IF Baiano - Campus Guanambi têm conhecimento dessas tecnologias na utilização de suas atividades de ensino e pesquisa? Porque alguns docentes utilizam as tecnologias existentes na instituição e outros não? Os docentes sabem das potencialidades que as tecnologias podem trazer para a sua prática pedagógica?

Diante de todas estas questões, poderíamos apontar como o problema a ser investigado é se a utilização da informática (computador; internet; softwares educacionais) pode influenciar positivamente a prática pedagógica dos docentes do IF Baiano - Campus Guanambi.

Neste sentido, nossa investigação se desenvolve a partir da prática docente dos professores do IF Baiano - Campus Guanambi. Partimos da hipótese de que a utilização da informática (computador; internet; softwares educacionais) por parte desses professores contribui significativamente para o estímulo de práticas inovadoras no IF Baiano - Campus Guanambi, o que constitui fator de qualidade do ensino.

\subsection{Metodologia}

Para a elaboração deste estudo foi usada uma abordagem descritiva, de caráter quantitativo, fundamentada em um quadro conceitual composto a partir da revisão da literatura e em dados coletados a partir da aplicação de questionários e da observação participante do cotidiano da escola.

Relacionada à pesquisa descritiva e do ponto de vista de seus objetivos Silva e Menezes diz que,

[...] uma pesquisa descritiva tem como objetivo primordial a descrição das características de de- 
terminadas população ou fenômeno, ou estabelecimento de relações entre variáveis - algumas pesquisas descritivas vão além da simples identificação da existência de relações entre variáveis, pretendendo determinar a natureza dessa relação. (SILVA; MENEZES, 2002a, p. 21)

Os sujeitos investigados na pesquisa foram 33 docentes que compõem o quadro de professores do IF Baiano - Campus Guanambi e para se fazer a coleta de dados e informações foi utilizada a pesquisa de campo, na qual tem como objetivo alcançar informações ou conhecimentos referentes a um determinado problema na qual se busca uma resposta, ou caso se queira comprovar uma hipótese, ou ainda, explorar novos fenômenos tal como ocorrem espontaneamente, na coleta de dados a eles referentes e no registro de variáveis que se presumem relevantes, para analisá-los. Para a realização da pesquisa de campo foram aplicados questionários como ferramenta de coleta de dados.

Com relação aos questionários Pádua (2004, p. 72) define-os "[...] como instrumentos de coleta de dados que são preenchidos pelos informantes, sem a presença do pesquisador".

Ele também diz:

Na elaboração do questionário é importante determinar quais são as questões mais relevantes a serem propostas, relacionando cada item à pesquisa que esta sendo feita e a hipótese que se quer demonstrar/provar/verificar. Isto quer dizer que o pesquisador deve elaborar o questionário somente a partir do momento em que tem um conhecimento razoável do tema proposto para pesquisa. (PÁDUA, 2004, p. 72)

Essa pesquisa teve como objetivo geral a descrição do uso da informática no processo ensino-aprendizagem no IF Baiano - Campus Guanambi, para podermos, por meio do mesmo, oferecer instrumentos analíticos para a elaboração de propostas de melhoria de uso das tecnologias existentes na instituição, onde os docentes possam desenvolver suas atividades pedagógicas com um instrumento a mais, visando o processo ensino-aprendizagem.

Por meio dos questionários aplicados a pesquisa permitiu alcançar os seguintes objetivos específicos: Analisar informações referentes à familiaridade dos docentes com a informática, identificar os elementos condicionantes objetivos e subjetivos para o uso adequado das mesmas, identificar possibilidades e potencialidades para o ensino com a utilização da informática no IF Baiano - Campus Guanambi.

\section{Revisão bibliográfica}

O trabalho enriquecido pelo acesso à informática pode oportunizar a construção de conhecimento e aprendizagem contínua. Kenski (2007, p. 45) afirma que a informática "[...] quando bem utilizada, provoca a alteração do comportamento de professores e alunos, levando-os ao conhecimento e maior aprofundamento do conteúdo estudado [...]".

De acordo com Cox (2003, p. 55), "[...] a adoção da informática na prática de sala de aula pode provocar importantes mudanças no processo de educação nas escolas, ao estimular a revisão das ações dos agentes escolares $[\ldots]^{\prime \prime}$. Como parte integrante do uso da informática nos temos os softwares aplicativos. Para esse tipo de software temos os processadores de textos. Com exemplo desses softwares temos o Word e sua importância dentro da educação, pode ser vista por Gasperetti (2001, p. 90) onde ele afirma que:

[...] ultrapassada a era das máquinas de escrever e do papel carbono, os programas de processamento de texto tornaram-se indispensáveis em escritórios e, principalmente, na escola. Não somente porque permitem preparar trabalhos, pesquisas e documentos diversos, mas porque os estudantes devem conviver com esse instrumento desde o início.

Quanto à Planilha Eletrônica, Excel, que é um outro tipo de sofware aplicativo, Aguiar \& Sette (2000, p. 26) diz que "[...] por sua vez, as planilhas auxiliam na compreensão dos conceitos de matriz e de expressões aritméticas, bem como na aplicação de problemas do cotidiano."

O uso de softwares educacionais constitui um outro importante aspecto que deve ser considerado. Os que mais estimulam e provocam serão selecionados para o progresso de um bom trabalho. A função do professor é essencial nesse processo e com relação a isso Almeida diz que:

O professor-aprendiz explora e analisa diferentes softwares educacionais, identifica as teorias 
subjacentes aos mesmos, analisa suas potencialidades, limitações e possíveis implicações na prática e na investigação pedagógica, aplicando o ciclo descrição-execução-reflexão-depuração. (ALMEIDA, 2000a, p. 30)

Ainda sobre a utilização e aplicação dos softwares educacionais, Aguiar e Sette afirmam que:

[...] a escolha de um software é um processo. Não existe receita pronta. Exige conhecimento a respeito, o que pressupõe a análise e a aplicação associada à proposta pedagógica da escola e à preparação de material metodológico para o uso e a avaliação do processo. (AGUIAR; SETTE, 2000, p. 30)

Segundo Moraes (1997, p. 6) "[...] a literatura $[\ldots]$ vem demonstrando que o computador deve ser utilizado como catalisador de mudanças do modelo educacional vigente [...]". A esse respeito, Valente afirma que:

[...] os computadores estão propiciando uma verdadeira revolução no processo ensino aprendizagem. Uma razão mais óbvia advém dos diferentes tipos de abordagens de ensino que podem ser realizados através do computador, devido aos inúmeros programas desenvolvidos para auxiliar o processo ensino-aprendizagem. Entretanto, a maior contribuição do computador como meio educacional advém do fato do seu uso ter provocado o questionamento dos métodos e processos de ensino utilizados. (VALENTE, 2003, p. 14)

Todo esse aparato tecnológico que as escolas possuem precisa ter utilizado de forma a auxiliar no processo ensino aprendizagem. Para isso é preciso que os professores estejam preparados. É ai que entra em cena os cursos de capacitação para o uso da informática em sala de aula pelos docentes. Neste contexto Cox afirma que:

[...] para intervir, os professores, assim como os outros agentes educacionais, precisam dispor de conhecimentos e habilidades específicas. Precisam, dentre outras coisas, conhecer as ferramentas computacionais que podem ter serventia à sua prática educacional escolar e saber explorar os instrumentos da informática de forma que atendam aos objetivos educacionais. (COX, 2003, p. 109)

Muitos desses cursos de capacitação para o uso da tecnologia não são oferecidos pelas instituições de ensino. Fazendo com que os docentes tenha que fazer investimentos financeiros próprio.

Neste cenário, Bettega afirma que:

[...] investimentos estruturais e financeiros tornam-se imprescindíveis para a elevação da qualidade do ensino no país. A criação de planos de carreira baseados no mérito, no nível de formação e na aplicação do saber apreendido ao ambiente da escola pode ser uma política promissora para estimular o educador a dedicar-se a sua atualização para a prática pedagógica. (BETTEGA, 2004, p. 42)

Existem diferentes métodos para serem utilizados em cursos de capacitação de professor para que possam exercer suas atividades com a informática. Para que seja bem sucedida, essa capacitação em informática educacional deve ter seus conteúdos organizados de acordo com as necessidades técnicas e pedagógicas de cada docente e a programação dos cursos de capacitação é antecipadamente determinada e passada para os professores. De acordo Valente,

[...] a formação profissional capaz de implantar mudanças na sua prática demanda outras especificidades. No entanto, elas só se tornam evidentes quando o professor, após o término de um curso de capacitação, retorna à sua escola para recontextualizar na sua prática pedagógica aquilo que aprendeu. (VALENTE, 2003, p. 22)

\section{Neste cenário, Almeida afirma que}

[...] a formação não se encerra com a conclusão de cursos, oficinas ou outros eventos, pois deve ter o caráter e continuidade, que se concretiza por meio de reuniões periódicas, seminários e debates através de redes telemáticas (Internet), encontros presenciais e oficinas. (ALMEIDA, 2000b, p. 178)

Tudo isso faz com que a informática desempenhe uma função importante na prática de ensino. Neste panorama, Silva (2002b, p. 26) afirma que "[...] a informática disponibiliza, hoje, diversos recursos que podem agilizar o aprendizado em qualquer conteúdo e tornar as aulas mais interessantes [...]".

Bettega (2004, p. 80), afirma que "[...] devemos reconhecer a informática como uma ferramenta para novas estratégias de aprendizagem capaz de contribuir de forma significativa para o processo de construção do conhecimento nas diversas áreas[...]". 
Segundo Moran (2009a, p. 11), "[...] a internet pode ajudar o professor a preparar melhor a sua aula, a ampliar as formas de lecionar, a modificar o processo de avaliação e de comunicação com o aluno e com os seus colegas."

$\mathrm{O}$ autor ainda afirma que:

O professor vai ampliar a forma de preparar a sua aula. Pode ter acesso aos últimos artigos publicados, as notícias mais recentes sobre o tema que vai tratar, pode pedir ajuda a outros colegas - conhecidos e desconhecidos - sobre a melhor maneira de trabalhar aquele assunto com os seus estudantes.

$[\ldots]$

O grande avanço neste campo da preparação de aula está na possibilidade de consulta a colegas conhecidos e desconhecidos, a especialistas, de perguntar e obter respostas sobre dúvidas, métodos, materiais, estratégias de ensino-aprendizagem. O papel do professor não é de somente coletar a informação, mas de trabalhá-la, de escolhê-la, confrontando visões, metodologias e resultados. (MORAN, 2009a, p. 11)

Outro ponto que se destaca no processo ensino-aprendizagem e que se for usada de forma correta poderá ajudar bastante a educação é a utilização da internet. Quanto a essa tecnologia Moran (2009a, p. 5) afirma que "[...] a internet é uma tecnologia que facilita a motivação dos alunos, pela novidade e pelas possibilidades inesgotáveis de pesquisa que oferece."

Com tantas tecnologias, entre elas internet, softwares educacionais, softwares aplicativos (Word, Excel, Powerpoint, etc) temos ainda o datashow. Ele é um recurso que com certeza poderá dinamizar, motivar e melhorar a qualidade das aulas, mas deve ser usado com cuidado para não se tornar um problema na relação professor-aluno.

Segundo Feitosa Neto,

[...] esse equipamento é fantástico. Ele dá qualidade à aula quando projeta no telão a síntese dos pontos do conteúdo a ser ministrado; quando projeta filmes; exibe a internet; usa figuras, sons, imagens etc. É um grande instrumento a serviço das práticas pedagógicas, sem dúvida. (FEITOSA NETO, 2008, p. 1)

\section{Resultados e discussão}

A pesquisa revela que os seguintes níveis de escolaridade: a maioria dos docentes possui Pós-graduação com $87,88 \%$, Superior -
Licenciatura com 9,09\% e Superior - Outros com 3,03\%. Dos docentes pós-graduados, temos 9 Especialistas, 17 Mestres e 3 Doutores. É necessário levarmos em consideração que mais da metade dos pesquisados têm Pósgraduação nas suas áreas específicas, mostrando um perfil sem ligação com a área de informática, ou seja, os professores da parte diversificada possui pós-graduação nas áreas de Agronomia, Zootecnia, Veterinária e os docentes da base comum possui pós-graduação nas áreas de Metodologia do Ensino superior, Educação, etc. Os resultados encontrados são apresentados na Tabela 1.

TABELA 1 - Docentes do IF Baiano - Campus Guanambi por Nível de Escolaridade - 2008

\begin{tabular}{|l|c|c|}
\hline \multicolumn{1}{|c|}{ Escolaridade } & No $^{\mathbf{c}}$ & $\mathbf{\%}$ \\
\hline Total & 33 & 100,00 \\
\hline Superior - Licenciatura & 3 & 9,09 \\
\hline Superior - Outros & 1 & 3,03 \\
\hline Pós-graduado & 29 & 87,88 \\
\hline
\end{tabular}

Nessa parte do questionário buscou-se investigar, sobre o conhecimento e a utilização da informática pelo pesquisado e como ele avalia o uso da informática na prática pedagógica. Para $27,27 \%$ dos docentes pesquisados, o primeiro contato com o computador ocorreu na escola onde cursou o ensino regular ou faculdade; enquanto que para $24,24 \%$ quando frequentou uma escola de informática e $18,18 \%$ foi em casa; $15,15 \%$ foi no seu local de trabalho, $12,12 \%$ foi na casa de parentes e amigos. Em menor intensidade, 3,03\% tiveram a sua oportunidade em outro local. Esses dados nos mostram que o computador começou a se tornar aliado dos docentes do IF Baiano - Campus Guanambi desde o Ensino Médio.

As mudanças sociais que se originam da vulgarização do uso e acesso à informática chegam a todas as instituições e ambientes sociais. Na era em que a informática se destaca, métodos, conduta, conhecimento, saberes e informações se modificam com extraordinária velocidade. Essas mudanças repercutemse sobre as clássicas maneiras de pensar e fazer educação. Abrir-se para novas metodologias de ensino, resultantes de mudanças estruturais nas formas de ensinar e aprender possibilitadas pela atualidade tecnológica é o grande desafio a ser assumido por toda a sociedade. 
No cenário de mudanças que as tecnologias causam, Libâneo afirma que os avanços da comunicação, da informática, as transformações tecnológicas e científicas que marcam o mundo moderno, "[...] intervêm nas várias esferas da vida social, provocando mudanças econômicas, sociais, políticas, culturais, afetando também, as escolas e o exercício profissional da docência [...]" (LIBÂNEO, 2006, p. 15). Os resultados obtidos podem ser vistos na Tabela 2.

TABELA 2 - Docentes do IF Baiano - Campus Guanambi Segundo Local Onde Tiveram o Primeiro Contato com o Computador - 2008

\begin{tabular}{|l|c|c|}
\hline $\begin{array}{l}\text { Primeiro Contato com o } \\
\text { Computador }\end{array}$ & No & \% \\
\hline Total & 33 & 100,00 \\
\hline No seu local de trabalho & 5 & 15,15 \\
\hline Na casa de parentes ou amigos & 4 & 12,12 \\
\hline Em escolas de informática & 8 & 24,24 \\
\hline $\begin{array}{l}\text { Na escola onde cursou o ensino } \\
\text { regular ou faculdade }\end{array}$ & 9 & 27,27 \\
\hline Em casa & 6 & 18,18 \\
\hline Outro & 1 & 3,03 \\
\hline
\end{tabular}

Na educação, quando possível, é preciso que a ajuda, tanto pessoal, material e didático, seja garantida e organizada, proporcionando novas orientações para uma educação melhor qualificada.

Sendo assim, perguntou-se aos docentes do IF Baiano - Campus Guanambi sobre sua familiaridade com alguma das tecnologias existentes no IF Baiano - Campus Guanambi.

Verificando a Tabela 3, observamos as seguintes respostas: $87,88 \%$ dos docentes responderam ter familiaridade com programas básicos (Windows 98, Windows XP, etc) e $12,12 \%$ afirmaram que não têm familiaridade com esses programas básicos (Windows 98, Windows $X P$, etc). $100 \%$ dos docentes têm familiaridade com o Word; $87,88 \%$ têm familiaridade com o Excel e 12,12\% não têm familiaridade com o Excel. 93,94\% têm familiaridade com o Powerpoint e 6,06\% não têm familiaridade com o Powerpoint. 15,15\% têm familiaridade com o banco de dados Access e $84,85 \%$ não têm familiaridade com o Banco de Dados Access. 39,39\% têm familiaridade com programas educativos e $60,61 \%$ não têm familiaridade com programas educativos. 90,91\% têm familiaridade com a internet e $9,09 \%$ não têm familiaridade com a internet. $33,33 \%$ têm familiaridade com outros softwa- res, tais como: Coreldraw, Moodle, etc.

TABELA 3 - Indicação da Familiaridade dos Docentes do IF Baiano - Campus Guanambi com Alguma Tecnologia - 2008

\begin{tabular}{|c|c|c|c|c|}
\hline $\begin{array}{l}\text { Familiaridade } \\
\text { com a } \\
\text { Tecnologia }\end{array}$ & Sim & $\%$ & Não & $\%$ \\
\hline Total & 33 & 100,00 & 33 & 100,00 \\
\hline $\begin{array}{l}\text { Programas } \\
\text { Básicos (Windows } \\
98, \text { Windows XP, } \\
\text { etc) }\end{array}$ & 29 & 87,88 & 4 & 12,12 \\
\hline Word & 33 & 100,00 & 0 & 0,00 \\
\hline Excel & 29 & 87,88 & 4 & 12,12 \\
\hline Powerpoint & 31 & 93,94 & 2 & 6,06 \\
\hline Access & 5 & 15,15 & 28 & 84,85 \\
\hline $\begin{array}{l}\text { Programas } \\
\text { Educativos }\end{array}$ & 13 & 39,39 & 20 & 60,61 \\
\hline Internet & 30 & 90,91 & 3 & 9,09 \\
\hline Outros & 11 & 33,33 & 22 & 66,67 \\
\hline
\end{tabular}

Esse resultado nos mostra que a maioria dos docentes do IF Baiano - Campus Guanambi sabe operar um computador por ter conhecimento nos programas básicos (Windows 98, Windows XP), que são programas utilizados para trabalhar com o computador. Os docentes também têm familiaridade suficiente no programa mais comum para edição de texto, o Word, utilizando-o para desenvolvimento e preparação de suas atividades, tais como: confecção de memorandos, provas e na elaboração de projetos, etc. O Excel - $88 \%$, PowerPoint - 94\%, Internet Explorer - 90\% e os programas educativos - 39\% são bastante usados. O Excel, por exemplo, é utilizado para se realizar as chamadas dos alunos e fazer o controle de notas. O Powerpoint é usado para ajudar nas aulas expositivas, permitindo que os docentes possam deixá-las mais dinâmicas. A Internet é usada para a busca de informações, sejam elas atuais ou não, para a elaboração de suas atividades pedagógicas e por último os programas educativos que têm pouca procura fazendo com que os mesmos não sejam tão utilizados como deveriam ser.

Com relação aos recursos tecnológicos existentes na IF Baiano - Campus Guanambi e 
com que freqüência os docentes utilizam esses recursos, a pesquisa nos mostrou que $100 \%$ utilizam o computador, sendo que a freqüência para esse recurso é a seguinte: 90,91\% utilizam semanalmente e $9,09 \%$ usam de forma esporádica; $100 \%$ utilizam a internet, com a mesma freqüência do computador, ou seja, $90,91 \%$ usam semanalmente e $9,09 \%$ usam de maneira esporádica (Tabela 4).

Quanto ao Datashow, $72,73 \%$ o usam com a seguinte freqüência: $15,15 \%$ Semanal; $15,15 \%$ Quinzenal; 6,06\% Mensal; 36,36\% esporádico; e $27,27 \%$ não utilizam o Datashow. $33,33 \%$ utilizam Softwares educacionais com a seguinte freqüência: 6,06\% Semanal; 3,03\% Mensal; 24,24\% esporádico; e 66,67\% não utilizam Softwares Educacionais (Tabela 4).

Não basta a escola ter o datashow. É necessário saber fazer a utilização dele, para que se possa aproveitar melhor, quando a questão é educação.

Neste panorama, Feitosa Neto faz as seguintes considerações:

- O data-show não substitui o docente;

- Ele deve ser utilizado como um instrumento auxiliar de interação entre o professor e o aluno na sala de aula;

- As aulas somente com data-show cansam os alunos, diminuindo o rendimento do conteúdo ministrado;

- O data-show não deve ser utilizado como um projetor de textos. Para isso temos os retroprojetores tradicionais, a um custo bem menor;

- É um crime acadêmico utilizar o data-show para exibir textos pesados, e o pior são os casos em que o professor ainda fica sentado ao lado da máquina lendo o que está escrito;

- Deixar a máquina ligada por mais de duas horas seguidas; ou ficar ligando e desligando o equipamento. Esse material é sensível e sua lâmpada tem um custo muito alto. (FEITOSA NETO, 2008, p. 1)

A informática cresce e varia sem parar. Para aprimorar essas práticas, os professores têm se preocupado em romper com a defasagem tecnológica do cotidiano escolar. A informática, inclusive, pode ser utilizada como ferramenta que torna este processo mais atrativo, instigante e variado.

Hoje, por meio da informática que está cada vez mais se destacando no dia-a-dia da escola e no processo ensino-aprendizagem, esta ocorrendo uma revolução na maneira de aprender. Computadores, internet, softwares educacionais, datashow e outras tecnologias são os protagonistas de uma nova revolução.

Hoje, com a internet e os avanços da tecnologia, podemos aprender de várias maneiras, em diversos lugares, de meios diferentes. Podemos ter uma parte das aulas de forma virtual ou freqüentar cursos a distância.

Estes novos espaços do processo de ensino-aprendizagem promovidos pela internet são capazes de diversificar o que desenvolvemos na sala de aula. Precisamos integrar a sala de aula com algumas atividades de consulta ou de exploração do mundo virtual, de caráter pedagógico, que possam ser desenvolvidas no laboratório de informática.

De acordo como o avanço das tecnologias virtuais - como internet, telecomunicações, videoconferência, redes de alta velocidade avança também a definição de presencialidade. Com isso podemos ter algumas aulas com professores externos, de outras instituições, com sua imagem e voz. Haverá, assim, uma troca maior de informações, tornando possível que cada professor colabore com seus conhecimentos específicos no processo de construção de conhecimento do aluno.

A informática possibilita novas maneiras de trabalho, permitindo a criação de espaços de aprendizagem em que os discentes pesquisam, realizem antecipações e simulações, comprovam idéias prévias, executam, criam soluções e constroem novas formas de representação mental. 
TABELA 4 - Freqüência de Utilização dos Recursos Tecnológicos Disponíveis no IF Baiano - Campus Guanambi - 2008

\begin{tabular}{|c|c|c|c|c|c|c|c|c|c|c|c|c|}
\hline $\begin{array}{l}\text { Recursos } \\
\text { Tecnológicos } \\
\text { Disponíveis }\end{array}$ & Sim & $\%$ & Não & $\%$ & $\begin{array}{c}\text { Sema- } \\
\text { nal }\end{array}$ & $\%$ & $\begin{array}{l}\text { Quin- } \\
\text { zenal }\end{array}$ & $\%$ & $\begin{array}{l}\text { Men- } \\
\text { sal }\end{array}$ & $\%$ & $\begin{array}{l}\text { Espo- } \\
\text { rádico }\end{array}$ & $\%$ \\
\hline Computador & 33 & 100,00 & 0 & 0 & 30 & 90,91 & 0 & 0 & 0 & 0 & 3 & 9,09 \\
\hline Internet & 33 & 100,00 & 0 & 0 & 30 & 90,91 & 0 & 0 & 0 & 0 & 3 & 9,09 \\
\hline Datashow & 24 & 72,73 & 9 & 27,27 & 5 & 15,15 & 5 & 15,15 & 2 & 6,06 & 12 & 36,36 \\
\hline $\begin{array}{l}\text { Não utiliza nenhum } \\
\text { recurso tecnológico }\end{array}$ & 0 & 0 & 0 & 0 & 0 & 0 & 0 & 0 & 0 & 0 & 0 & 0 \\
\hline Não Responderam & 0 & 0 & 0 & 0 & 0 & 0 & 0 & 0 & 0 & 0 & 0 & 0 \\
\hline
\end{tabular}

Pode-se verificar que os docentes do IF Baiano - Campus Guanambi sempre utilizam algum dos recursos tecnológicos existentes no instituto com alguma freqüência.

Interpretando os dados das Tabelas 3 e 4 quanto à utilização dos softwares educacionais. Vimos por meio desses dados que os softwares não são muito utilizados pelos docentes do IF Baiano - Campus Guanambi e que também não são todos os docentes que possuem familiaridade com os programas educativos. Isso se dá pela falta de capacitação e muitas vezes os docentes não têm nem conhecimento de que no IF Baiano - Campus Guanambi possui esses softwares educacionais.

Em relação aos softwares educacionais utilizados pelos docentes, os dados foram analisados por incidência, porque têm software que são usados por mais de um docente. Tal resultado vem confirmar os dados informados na Tabela 05, onde a pesquisa nos revelou que 25 docentes não responderam essa pergunta; 4 docentes utilizam o Saeg que é um software de Estatística; 2 docentes usam o Winfit; 1 docente utiliza o Imagine, Crocodille Physics, Crocodille Chemistry, Crocodille Mathematics, Illuminatus, Língua - Espanhol, Cabri II Plus e Ebeam.

A interpretação dos dados da Tabela 5 vem confirmar os dados da Tabela 3 e 4 onde os professores não têm familiaridade com a tecnologia de softwares educacionais, o recurso tecnológico existe dentro do IF Baiano - Campus Guanambi, mas não é totalmente utilizado e quando é usado, como mostra a Tabela 5, são apenas alguns softwares.
TABELA 5 - Freqüência de Utilização de Softwares Educacionais Pelos Docentes da IF Baiano - Campus Guanambi $-2008$

\begin{tabular}{|c|c|c|}
\hline $\begin{array}{l}\text { Utilização } \\
\text { de Software } \\
\text { Educacional }\end{array}$ & No & $\%$ \\
\hline Total & 39 & 100,00 \\
\hline Gera Boi & 0 & 0,00 \\
\hline Procreare & 0 & 0,00 \\
\hline Imagine & 1 & 2,56 \\
\hline Tabs+ & 0 & 0,00 \\
\hline Crocodile Physics & 1 & 2,56 \\
\hline Crocodile Technology & 0 & 0,00 \\
\hline Multibovinos & 0 & 0,00 \\
\hline Crocodille Chemistry & 1 & 2,56 \\
\hline Crocodille Mathematics & 1 & 2,56 \\
\hline Illuminatus & 1 & 2,56 \\
\hline Edison & 0 & 0,00 \\
\hline Nexus & 0 & 0,00 \\
\hline Biblos Plus & 0 & 0,00 \\
\hline Língua - Espanhol & 1 & 2,56 \\
\hline Cabri II Plus & 1 & 2,56 \\
\hline Ebeam & 1 & 2,56 \\
\hline Winfit & 2 & 5,13 \\
\hline Saeg & 4 & 10,26 \\
\hline $\begin{array}{ll}\text { Gerente } & \text { de } \\
\text { Agronegócio } & \end{array}$ & 0 & 0,00 \\
\hline Sherlock & 0 & 0,00 \\
\hline English Millenium & 0 & 0,00 \\
\hline Não Responderam & 25 & 64,10 \\
\hline
\end{tabular}

A utilização da informática na educação, mesmo apelando para programas criados especificamente para área educacional, sempre exige dos agentes escolares atitude crítica e capacitação contínua. Para que isso ocorra, o professor poderá contextualizá-lo no processo de construção do conhecimento.

Sobre quais os softwares educacionais que eles utilizam, há uma aceitação entre os docentes sobre a eficácia desses softwares como suporte à metodologia aplicada em sala 
de aula. A análise nos revelou, através da Tabela 6, que: $57,58 \%$ responderam que sim; $15,15 \%$ responderam que não; e $27,27 \%$ não responderam essa pergunta.

TABELA 6 - Indicação de Suporte que Essas Tecnologias Constituem na Metodologia Aplicada na Sala de Aula Pelos Docentes do IF Baiano - Campus Guanambi - 2008

\begin{tabular}{|l|c|c|}
\hline $\begin{array}{l}\text { Tecnologia Eficaz na } \\
\text { Metodologia }\end{array}$ & No & \% \\
\hline Total & 33 & 100,00 \\
\hline Sim & 19 & 57,58 \\
\hline Não & 5 & 15,15 \\
\hline Não Responderam & 9 & 27,27 \\
\hline
\end{tabular}

Com relação às justificativas para a resposta sim dessa pergunta ocorreram muitas, entre elas temos: melhora o aprendizado do aluno; oferece outras opções de metodologias de ensino; desperta a curiosidade dos alunos; prende a atenção; complemento em sala de aula.

A decisão de usar os softwares educacionais como suporte ao processo de ensinoaprendizagem deve ser fundamentado em pontos que levem em consideração os mais diferenciados aspectos. Muitos docentes supõem que a utilização de softwares como suporte à metodologia aplicada em sala de aula é lucrativo, capaz de suprir ou diminuir o tempo do professor junto ao aluno. Alguns softwares têm como objetivo proporcionar a função de treinamento, a realização de trabaIhos que complementem as práticas usuais, a pesquisa etc, substituindo consequentemente aquele professor tradicional. Portanto, ao se ponderar o importante e fundamental papel do educador de instigar a curiosidade, de despertar o interesse do aluno, de estimulá-lo para a resolução de problemas, constata-se que os softwares educacionais representa um apoio importante nesse sentido.

No que se refere ao computador como recurso disponível na instituição e porque os docentes não utilizam, não houve respostas dos docentes para essa pergunta. Pelos resultados obtidos vimos que o computador é um recurso utilizado no IF Baiano - Campus Guanambi, seja ele para desenvolvimento de trabalhos pedagógicos ou pessoais.

A utilização do computador na educação indica para um novo sentido. O uso desta tecnologia passa a não ser como uma máquina de ensinar, mas como uma inovação educacional. O computador torna-se uma ferramenta edu- cacional, uma tecnologia que complementa, aperfeiçoa e que possivelmente provoca mudanças na qualidade do ensino.

Com a questão da implantação do Laboratório de Informática, foi perguntado se ocorreu o curso de capacitação para a utilização desse ambiente. Pode-se verificar que 75,76\% responderam que ocorreu curso de capacitação; $15,15 \%$ responderam que não teve capacitação; e 9,09\% não responderam essa questão. Isso fica evidenciado pelo percentual significativo de respostas sim visto na Tabela 8 , mostrando que houve uma capacitação para os docentes. Quanto à resposta não, as justificativas dos professores foram que eles não ficaram sabendo desse curso, ou seja, não foram comunicados.

TABELA 7 - Indicação da Ocorrência do Curso de Capacitação, Promovido Pelo IF Baiano - Campus Guanambi Para o Uso do Laboratório de informática - 2008

\begin{tabular}{|l|c|c|}
\hline $\begin{array}{l}\text { Curso Para Uso do } \\
\text { Laboratório }\end{array}$ & No & \% \\
\hline Total & 33 & 100,00 \\
\hline Sim & 25 & 75,76 \\
\hline Não & 5 & 15,15 \\
\hline Não Responderam & 3 & 9,09 \\
\hline
\end{tabular}

Atualmente existe um indicador expressivo de docentes executando projetos e atividades intercedidos pela informática. Mas a maior parte das escolas e docentes ainda está investigando sobre como usá-las de maneira adequada.

Para que os laboratórios de informática que são implantados nas escolas possam ser utilizados, primeiro deve ocorrer à capacitação dos docentes, ou seja, a formação dos professores para trabalhar com a informática na educação. Essa formação deve ser inicial e continuada em informática educacional, ou seja, deve se preparar os docentes desde os conhecimentos básicos em informática até a utilização na sua prática pedagógica e sempre mantê-los atualizados.

Perguntados se fizeram esse curso de capacitação, 48,48\% responderam que sim; $27,27 \%$ responderam que não; e $24,24 \%$ não responderam essa questão. Os resultados da pesquisa, em relação ao conteúdo do curso de capacitação e se o mesmo foi adequado às necessidades pedagógicas, foram os seguintes: 45,45\% disseram que sim; 9,09\% disseram que não; e 45,45\% não responderam essa questão. Esses resultados podem ser vistos 
na Tabela 8 e Tabela 9.

TABELA 8 - Docentes do IF Baiano - Campus Guanambi, Segundo Freqüência ao Curso de Capacitação - 2008

\begin{tabular}{|l|c|c|}
\hline $\begin{array}{l}\text { Realização do Curso de } \\
\text { Capacitação }\end{array}$ & No & \% \\
\hline Total & 33 & 100,00 \\
\hline Sim & 16 & 48,48 \\
\hline Não & 9 & 27,27 \\
\hline Não Responderam & 8 & 24,24 \\
\hline
\end{tabular}

TABELA 9 - Docentes do IF Baiano - Campus Guanambi, Segundo Opinião Sobre Adequação do Conteúdo do Curso de Capacitação às Suas Necessidades Pedagógicas - 2008

\begin{tabular}{|l|c|c|}
\hline $\begin{array}{l}\text { Opinião Sobre Adequação } \\
\text { do Curso de Capacitação }\end{array}$ & No & \% \\
\hline Total & 33 & 100,00 \\
\hline Sim & 15 & 45,45 \\
\hline Não & 3 & 9,09 \\
\hline Não Responderam & 15 & 45,45 \\
\hline
\end{tabular}

Apesar de grande parte dos docentes não ter respondido essa questão, analisando os resultados, parece ser imprescindível que a ajuda aos docentes abarcados no processo ocorra na forma de capacitação, de maneira a oportunizar a construção de conhecimento, ao mesmo tempo em que desperta possibilidades e potencialidades com o acesso e uso da informática como ferramenta de ensino. Além disso, a escola deve oferecer espaços físicos, estrutura tecnológica e pedagógica suficiente e uma boa política salarial para se obter uma boa qualidade.

Todas essas mudanças prescindem da conscientização de que as tecnologias podem auxiliar os docentes no processo de ensinoaprendizagem. Para o uso dessas tecnologias os docentes devem estar preparados. Isto poderá ser realizado por meio de uma capacitação em nível inicial seguindo até a parte avançada em informática aplicada à educação.

Devemos também levar em consideração as pessoas que estão envolvidas nesse processo deverão ser profissionais pedagogicamente habilitados, mas com conhecimentos profundos em informática.

Independente de quaisquer que sejam os métodos de capacitação ou formação escolhida, sua consolidação deve ser coesa com as exigências da equipe em formação. Os espaços para essa capacitação devem estabelecer uma ligação entre teoria, prática e domínio de recursos computacionais para que possa ocorrer um aprimoramento e uma mudança da prática pedagógica. Toda a mudança que se espera com esses cursos de Informática Educacional, deve estar constantemente em reflexão.

Do ponto de vista da grande parte dos pesquisados, o curso de capacitação é digno dos conceitos Ótimo, Bom, Regular e Ruim, representados pelos índices de 39,39\%, 6,06\%, $3,03 \%$ e 3,03\%, conforme Tabela 10 .

TABELA 10 - Freqüência de Indicação dos Docentes do IF Baiano - Campus Guanambi Sobre Avaliação do Curso de Capacitação - 2008

\begin{tabular}{|l|c|c|}
\hline $\begin{array}{l}\text { Avaliação do Curso de } \\
\text { Capacitação }\end{array}$ & No & \% \\
\hline Total & 33 & 100,00 \\
\hline Ótimo & 1 & 3,03 \\
\hline Bom & 13 & 39,39 \\
\hline Regular & 2 & 6,06 \\
\hline Ruim & 1 & 3,03 \\
\hline Não Responderam & 16 & 48,48 \\
\hline
\end{tabular}

Dentre os motivos para esta avaliação nos conceitos acima citados, os docentes destacaram que o curso permite o acesso ao uso da informática e possibilita mais opções de metodologias de ensino.

$\mathrm{Na}$ Tabela 10, que se refere a avaliação do curso de capacitação, podemos observar que $48,48 \%$ dos docentes não responderam essa questão, ou seja, o curso para eles não teve como ser avaliado por falta de absorção de conteúdos para os docentes.

Conforme pode ser verificado na Tabela 11, quando os docentes do IF Baiano - Campus Guanambi foram questionados se o Instituto desenvolve ou já desenvolveu algum projeto pedagógico envolvendo a informática os resultados são os seguintes: 33,33\% responderam que sim; $15,15 \%$ responderam que não; $42,42 \%$ não sabiam; e 9,09\% não responderam essa questão, por achar que não precisaria respondê-la.

TABELA 11 - Docentes do IF Baiano - Campus Guanambi, Segundo Indicação de Ciência de Ocorrência de Desenvolvimento de Projeto Pedagógico na Instituição Envolvendo a Informática - 2008

\begin{tabular}{|l|c|c|}
\hline Projetos Pedagógicos & No & \% \\
\hline Total & 33 & 100,00 \\
\hline Sim & 11 & 33,33 \\
\hline Não & 5 & 15,15 \\
\hline Não, sei & 14 & 42,42 \\
\hline Não Responderam & 3 & 9,09 \\
\hline
\end{tabular}


Quanto aos projetos pedagógicos desenvolvidos para a capacitação dos docentes foram citados: Treinamento de Word, Excel, Internet, Interdisciplinaridade, Internet e Educação, Aperfeiçoamento com vídeo conferência. Ao pedir aos docentes que falassem dos projetos pedagógicos para capacitação dos docentes, comprovamos que a informática está no meio de quase todos os conteúdos das diversas áreas de ensino, mas não há clareza na definição de objetivos dos projetos, o que comprova a falta de clareza quanto às atuações da escola em relação à utilização da informática no processo ensino-aprendizagem.

Os projetos de capacitação dos docentes do IF Baiano - Campus Guanambi foram desenvolvidos de forma que a informática fosse abordada de maneira ampla, ou seja, poderia ser usada por todas as disciplinas. Não teve nenhum projeto que direcionasse o conteúdo do curso para a capacitação específica de uma determinada disciplina. E esse é o grande problema dos cursos de capacitação docente. Hoje, a capacitação de professores esta além da simples utilização da informática é preciso que os cursos de capacitação sejam direcionados para atingir os conteúdos de suas respectivas disciplinas.

Deve existir dentro do Instituto uma política ou até mesmo um departamento de informática educacional, onde os professores possam estar sendo acompanhados e assessorados no uso da informática em sua prática pedagógica. Com isso o professor vai ter sempre uma estrutura de apoio que ofereça condições de construção de novos conhecimentos.

Desta forma, atuações direcionadas para a formação de professores baseadas numa proposta institucionalizada, com uma contribuição multidisciplinar, que forneçam diretrizes e estratégias direcionadas para o contexto social atual, com uma avaliação sistemática, proporciona um caminho promissor no que se refere ao resgate na construção e reconstrução de soluções pedagógicas, sociais e políticas e realizado em conjunto por professores, orientadores pedagógicos, diretores, técnicos e demais profissionais no próprio espaço da escola ou diretoria de ensino.

De acordo a Tabela 12, a pesquisa nos revelou que $93,94 \%$ dos docentes do IF Baiano Campus Guanambi acreditam que a informática facilita a aprendizagem do aluno e 6,06\% não responderam essa questão.
TABELA 12 - Docentes do IF Baiano - Campus Guanambi, Segundo Opinião Sobre a Utilização da Informática Como Facilitadora na Aprendizagem do Aluno - 2008

\begin{tabular}{|l|c|c|}
\hline $\begin{array}{l}\text { Aprendizagem do } \\
\text { Aluno }\end{array}$ & No & \% \\
\hline Total & 33 & 100,00 \\
\hline Sim & 31 & 93,94 \\
\hline Não & 0 & 0,00 \\
\hline Não Responderam & 2 & 6,06 \\
\hline
\end{tabular}

Esse resultado deixa claro que os docentes do IF Baiano - Campus Guanambi, na sua maioria, são receptivos ao uso da informática para melhorar a aprendizagem dos alunos. A prática pedagógica que é feita de maneira linear já vem sendo discutida como superada, sem eficiência. A informática aparece como uma alternativa para auxiliar a aprendizagem, um recurso a mais para a diminuição das carências pedagógicas.

Neste sentido, torna-se essencial introduzir a informática na prática de ensino como uma maneira de atrair benefícios para o desempenho pedagógico, garantindo sua eficácia.

Questionados sobre as vantagens notadas a partir do uso da informática, paralelo as práticas educativas, onde a questão foi analisada por incidência, é possível observar na Tabela 13 que 20 docentes responderam que proporcionam maior interesse pela disciplina; 20 docentes responderam que contribui para acrescentar o desenvolvimento do conhecimento; 13 docentes responderam que ocorre modernização da instituição; 10 docentes responderam que ocorre maior rapidez na aprendizagem do aluno; e 1 docente não respondeu essa questão.

TABELA 13 - Indicações dos Docentes do IF Baiano - Campus Guanambi das Vantagens Notadas a Partir do Uso da Informática nas Práticas Educativas - 2008

\begin{tabular}{|l|c|c|}
\hline $\begin{array}{l}\text { Vantagens do Uso da } \\
\text { Informática }\end{array}$ & No & \% \\
\hline Total & 64 & 100,00 \\
\hline $\begin{array}{l}\text { Maior rapidez na } \\
\text { aprendizagem do aluno }\end{array}$ & 10 & 15,63 \\
\hline $\begin{array}{l}\text { Proporcionar maior } \\
\text { interesse pela disciplina }\end{array}$ & 20 & 31,25 \\
\hline Não apresenta vantagens & 0 & 0,00 \\
\hline $\begin{array}{l}\text { Contribuir para acrescentar } \\
\text { o desenvolvimento do } \\
\text { conhecimento }\end{array}$ & 20 & 31,25 \\
\hline $\begin{array}{l}\text { Modernização da } \\
\text { instituição }\end{array}$ & 13 & 20,31 \\
\hline Não Responderam & 1 & 1,56 \\
\hline
\end{tabular}


Deduz-se que a informática tem o papel significativo e algumas vezes pode definir o sucesso ou fracasso de um profissional na chamada sociedade do conhecimento. Esses avanços significam uma modificação respeitável no papel do professor, visto que o professor pode agir como coordenador do processo de ensinar e aprender. Por outro lado, tudo indica que o preparo profissional dos responsáveis pelas experiências que estão dando certo atualmente provém mais de suas experiências pessoais do que de uma formação esquematizada e organizada pela escola. Cogita-se que a informática, deve ser levada em consideração para tornar mais fácil as tarefas dos alunos e aproveitar melhor seu tempo e seus esforços.

Questionados se o IF Baiano - Campus Guanambi têm contribuído para a aquisição de equipamentos de informática, os docentes apontaram o seguinte: 90,91\% responderam que sim e 9,09\% não responderam essa questão.

A Direção do IF Baiano - Campus Guanambi sempre buscou estar atualizada com relação à informática, mesmo porque, hoje não são todas, mas algumas escolas possuem algum tipo de equipamento que possa melhorar não só o trabalho pedagógico como também o administrativo. O próprio incentivo do Governo Federal proporciona essa aquisição de equipamentos de informática. Cabe aos gestores da escola fazer um planejamento para que os equipamentos adquiridos sejam bem aplicados, tanto na parte pedagógica como também no administrativo e os equipamentos não fiquem sem utilização.

Quando questionados sobre o suporte do datashow para melhorar o desempenho nas aulas, os docentes responderam o seguinte: $84,85 \%$ responderam que sim, que dá suporte; e $15,15 \%$ responderam que não dá suporte.

Observando-se a Tabela 14, quando questionados sobre as dificuldades enfrentadas quanto à manipulação dos softwares educacionais, $45,45 \%$ dos docentes responderam ter falta de conhecimento; $24,24 \%$ responderam haver falta de disponibilidade de horário no Laboratório de Informática; 15,15\% responderam haver falta de tempo; e $12,12 \%$ não responderam essa questão.
TABELA 14 - Docentes do IF Baiano - Campus Guanambi, Segundo Indicação das Dificuldades Enfrentadas Para a Manipulação dos Softwares Educacionais - 2008

\begin{tabular}{|l|c|c|}
\hline $\begin{array}{l}\text { Dificuldades no uso de sof- } \\
\text { twares }\end{array}$ & No & \% \\
\hline Total & 33 & 100,00 \\
\hline Falta de conhecimento & 15 & 45,45 \\
\hline $\begin{array}{l}\text { Falta de disponibilidade de } \\
\text { tempo }\end{array}$ & 5 & 15,15 \\
\hline $\begin{array}{l}\text { Falta de disponibilidade de horá- } \\
\text { rio no laboratório de informática }\end{array}$ & 8 & 24,24 \\
\hline Não Responderam & 4 & 12,12 \\
\hline
\end{tabular}

Essa questão mostra que os docentes do IF Baiano - Campus Guanambi não sabem trabaIhar com os softwares educacionais, ou seja, falta conhecimento para se manipular esses softwares que a escola possui instalados no Laboratório de Informática. Os docentes que sabem manipular esses softwares alegam que ocorre falta de horário no laboratório de informática. Isso realmente é comprovado, pois a escola só possui um laboratório e o mesmo é utilizado para se ministrar aulas da disciplina de informática.

Questionados sobre como um curso de capacitação deveria ser elaborado para ser adequado para os professores, os docentes deram várias sugestões, onde foram classificadas de acordo a Tabela 15.

Para definir as respostas dessa pergunta foi utilizada a seguinte classificação: a) a informática com a prática pedagógica dos docentes e seus conteúdos; b) os programas que são utilizados pelos docentes; c) carga horária e período que os cursos devem ser oferecidos; d) níveis de conhecimento dos docentes; e, por último, e) forma como os cursos devem ser trabalhados, onde as respostas apontam para mais prática, parte presencial e a outra a distância, etc.

As respostas dos docentes à pergunta do questionário sobre a maneira pela qual um curso de capacitação em informática deve ser elaborado causaram surpresa pela opulência de informações e sugestões. Suas idéias colaboraram para o desenvolvimento deste trabalho e melhor compreensão do ponto de vista do docente em relação à hipótese da pesquisa. 
TABELA 15 - Docentes Do IF Baiano - Campus Guanambi, Segundo Sugestão Para que um Curso de Capacitação Seja Adequado Para os Professores - 2008

\begin{tabular}{|l|c|c|}
\hline Sugestões Para Capacitação & No & \% \\
\hline Total & 33 & 100,00 \\
\hline $\begin{array}{l}\text { Informática com a prática } \\
\text { pedagógica dos docentes e seus } \\
\text { conteúdos }\end{array}$ & 9 & 27,27 \\
\hline $\begin{array}{l}\text { Programas que são utilizados } \\
\text { pelos docentes }\end{array}$ & 4 & 12,12 \\
\hline $\begin{array}{l}\text { Carga horária e o período } \\
\text { Nível de conhecimento dos do- } \\
\text { centes com a informática }\end{array}$ & 7 & 21,21 \\
\hline $\begin{array}{l}\text { Forma como os cursos devem } \\
\text { ser trabalhados / ter caráter de } \\
\text { continuidade }\end{array}$ & 11 & 33,33 \\
\hline
\end{tabular}

Nas sugestões dadas pelos docentes do IF Baiano - Campus Guanambi percebemos que há uma concordância sobre a necessidade de se organizar um curso de capacitação que institua ligação entre a informática e a prática pedagógica. Os docentes enxergam que não há ligação entre o que é abordado no curso e o que eles necessitam para realizar com qualidade os projetos pedagógicos com a ajuda da informática. Além do mais, os docentes esperam que um curso de capacitação dessa qualidade permita a ampliação de suas competências e habilidades para usarem a informática como componente facilitador do processo de ensino-aprendizagem e, assim, possa motivar o aluno.

Para eles, seria interessante formar as turmas de capacitação de acordo com o nível de conhecimento sobre informática, visto que vários docentes já possuem noções sobre o uso da informática, ao passo que outros necessitam de orientações básicas, ou seja, precisam de mais tempo de aprendizado.

Além disso, os docentes sugerem que os cursos sejam organizados de acordo com as necessidades do dia-a-dia do professor, sua área de atuação e seus conteúdos, etc. Além disso, o processo de capacitação não deve se encerrar quando os cursos de capacitação se acabam.

\section{Conclusões}

Por causa do volume excessivo de informações nem sempre a escola consegue apropriar- se das mudanças importantes que ocorre na sociedade. A idéia que fica e de que a escola está caminhando devagar com relação à rapidez em que ocorrem as mudanças socioculturais. Não podemos, introduzir a modernização no processo ensino aprendizagem com base na informática de qualquer maneira. Qualquer mudança deve ser consciente, refletida; devem aparecer aos poucos, deve ser amadurecida a cada dia, com discernimento, tomando como referência as ações.

Notamos que, ao usar a informática, exercemos interação com o aluno de maneira mais instantânea, com mais criatividade e estímulo. No entanto, temos conhecimento de que para implantar mudanças demanda preparo. Professor algum irá entrar em um Laboratório de Informática com seus discentes se não tiver absoluta confiança no que fará neste ambiente.

O papel do docente nesse cenário é essencial e importante, pois é ele quem cria os ambientes de aprendizagem fazendo com que ocorra uma valorização dos discentes.

Isto posto, observamos que a hipótese desta pesquisa de que a utilização da informática (computador; internet; softwares educacionais) por parte dos professores contribui significativamente para o estímulo de práticas inovadoras no IF Baiano - Campus Guanambi está confirmada pelos resultados obtidos. Mas os professores enfrentam algumas dificuldades na inserção da informática na sua prática pedagógica, tendo como um dos principais agravantes a deficiência do curso de capacitação para o uso do Laboratório de Informática, bem como para a utilização dos softwares educacionais existente no IF Baiano - Campus Guanambi. Outro problema da instituição consiste no fato de possuir apenas um laboratório de informática, limitando por demais o uso adequado pelos que necessitam dele.

Os resultados desta pesquisa apontam para pontos positivos como, por exemplo, vimos que a necessidade de iniciativas no sentido de atender as demandas desses profissionais em sala de aula, tendo como objetivo a melhor utilização do Laboratório de Informática, com seus softwares educacionais, resultando em um processo de ensino-aprendizagem de meIhor qualidade.

Devemos ter cuidado para que a informática não seja aplicada dentro do ambiente escolar apenas como mais um modismo, mas 
com a importância e a capacidade educacional transformadora que têm. É necessário que se pense e reflita sobre o processo de ensinoaprendizagem de modo mais abrangente.

Para que isso ocorra, é necessário, antes de qualquer coisa, que todo mundo es- teja consciente e preparado e que considere as mudanças que estão ocorrendo na escola, tirando proveito das vastas possibilidades comunicativas e informativas da informática para a materialização de um ensino que seja crítico e de qualidade.

\section{Referências}

AGUIAR, Márcia Angela; SETTE, Sônia Schechtman; SETTE, José Sérgio Antunes. Formação de Professores em Informática na Educação: um caminho para mudanças. Brasília: MEC/SEED, 2000. (Col. Informática para a mudança na educação).

ALMEIDA, Maria Elizabeth Biancocini. O Aprender e a Informática: a arte do possível na formação do professor. Brasília: MEC/SEED, 2000a. (Col. Informática para a mudança na educação).

ALMEIDA, Maria Elizabeth. Biancocini. Informática e Formação de Professores. Brasília: MEC/SEED, 2000 b. (Estudos educação à distância, v. 2)

BeTTEgA, Maria Helena Silva. A Educação Continuada na Era Digital. São Paulo: Cortez, 2004. (Questões da nossa época, v. 116)

COX, Kenia Kodel. Informática na Educação Escolar. Campinas, SP: Autores Associados, 2003 (Polêmicas do nosso tempo, 87)

ELHAJJI, Mohammed. Novas Estratégias Organizacionais no Cenário Global. Disponível em: <http://www. scielo.br/pdf/ci/v28n2/28n2a02.pdf> Acesso em: 15 dez. 2007.

FEITOSA NETO, Inácio. O Professor Data-Show. Disponível em: <http://www.mauriciodenassau.edu.br/artigo/listar/rec/264> Acesso em: 10 out. 2008.

GASPERETTI, Marco. Computador na Educação: guia para o ensino com as novas tecnologias. São Paulo: Ed. Esfera, 2001.

KENSKI, Vani Moreira. Educação e Tecnologias: o novo ritmo da informação. Campinas, SP: Papirus, 2007. (Col. Papirus educação)

LIBÂNEO, José Carlos. Adeus Professor, Adeus Professora?: novas exigências educacionais e profissão docente. 9. ed. São Paulo: Cortez, 2006.

MORAES. Maria Cândida. Subsídios Para Fundamentação do Programa Nacional de Informática na Educação. Brasília: MEC/SEED, 1997.

MORAN, José Manuel. Desafios da Internet Para o Professor. Disponível em: <http://www.eca.usp.br/prof/ moran> Acesso em: 11 abr. 2009a.

MORAN, José Manuel; MASSETO, Marcos T.; BEHRENS, Marilda Aparecida. Novas Tecnologias e Mediações Pedagógica. Campinas, SP: Papirus, 2000. 
SILVA, Marilza Oliveira Seixas da. O Uso do Computador no Ensino Para Formar, Processar, Gerenciar Informações e Construir Conhecimento: visão diagnóstica. 2002b. Dissertação (Mestrado em Engenharia de Produção) - Programa de Pós-Graduação em Engenharia de Produção, Universidade Federal de Santa Catarina, 2002, Florianópolis, BR-SC.

SILVA, Edna Lúcia.; MENEZES, Estera. Muszkat. Apostila de Pesquisa e Elaboração de Dissertação. Florianópolis: UFSC/Programa de Pós-Graduação em Engenharia de Produção, 2002a.

SOUZA, Sérgio Augusto Freire de. Educação e Informática: temas transversais e uma proposta de implementação. Revista Conect@: revista on-line de educação a distância, Rio de Janeiro, n. 4, fev. 2002. Disponível em: < http://www.revistaconecta.com/> Acesso em: 15 dez. 2007.

VALENTE, José Armando. Formação de Educadores Para o Uso da Informática na Escola. Campinas, SP: Unicamp/Nied, 2003.

Recebido em março de 2010.

Aprovado para publicação em junho de 2010. 